\title{
Leading Employees Through the Crises: Key Competences of Crises Management in Healthcare Facilities in Coronavirus Pandemic
}

This article was published in the following Dove Press journal: Risk Management and Healthcare Policy

\section{Nadežda Jankelová \\ Zuzana Joniaková (D) \\ Jana Blštáková \\ Zuzana Skorková \\ Katarína Procházková}

Department of Management, Faculty of Business Management, University of Economics in Bratislava, Bratislava, Slovakia
Correspondence: Nadežda Jankelová Department of Management, Faculty of Business Management, University of Economics in Bratislava, Dolnozemská Cesta I, Bratislava, 852 35, Slovakia Tel +42I 9II 232927

Email nadezda.jankelova@euba.sk
Purpose: The fast and shocking onset of the crisis caused by the COVID-19 virus created the need for a complete crisis management of healthcare facilities to manage the current stage of the crisis. The purpose of our research is to examine the relations between the competences of crisis management in healthcare facilities and the performance of employees, measured during the acute stage of the crisis by their feeling of satisfaction, safety and creation of conditions for work, whereby we assume that these variables are mutually interlinked by the sharing of information, teamwork and cognitive diversity of the work teams.

Materials and Methods: A questionnaire survey was created and used based on a sample of 216 mid-level managers of health care facilities in Slovakia, which took place during the first month after the outbreak of the crisis (during the month of March/April 2020). The Baron and Kenny mediator model has been used for research purposes and the FreedmanSchatzkin test has been used to test the mediator effect. Regression analysis has been used to verify the hypotheses. The control variables were the size of the healthcare facility based on the number of employees, gender and age of the manager, his position in the management hierarchy and the duration of practice in a management position. The ANOVA analysis of variance was used to analyze multiple dependencies. The level of significance was $5 \%$. The research sample consisted of 216 managers at different types of healthcare facilities.

Results: The hypothesis for the dependency between the crisis competences of management and performance of teams during the acute stage of the crisis, facilitated by sharing information, teamwork and cognitive diversity of crisis management was confirmed. It is a multilateral incomplete mediation, where almost two thirds of the total effect are facilitated by mediators, of which the sharing of information has the greatest effect (35\%).

Conclusion: Based on our mediation model, healthcare facilities, which strive to implement crisis management during the acute stage of the crisis, should place emphasis especially on reliable background information and the fast sharing of information, supporting the performance of healthcare teams. The strategies for achieving these goals should also include education focused on the development of managerial competences.

Keywords: crisis management, sharing information, teamwork, team performance, cognitive diversity

\section{Background}

For organizations, the global COVID-19 pandemic brought needs of urgent and big changes. On the one hand, the managers were suddenly forced to decide on the crisis regime of the organizations led by them, to protect the health of their employees and also to ensure the smooth operation of their organization as much 
as possible. On the other hand, the managers of healthcare organizations were forced to solve the situation of how to strengthen the healthcare teams to manage the pandemic under the existing chronic crisis of workforce in this sector. Despite the fact that the level of managerial competencies of leaders in health care facilities has been the subject of a long professional discourse, legitimate fear, how this situation could be handled was justified. The initial stage of emerging crisis was an extremely challenging period and opportunity for research to supplement knowledge, how to manage similar crises.

The crisis caused by the new Coronavirus pandemic has several specifics. It is not only a local matter but a widespread global crisis, which affects the most important human value, health, and therefore it is very sensitively perceived by the people. It affects them directly, introduces not only healthcare impacts, including deaths, but also economic, social and mental consequences. Its onset was fast and it quickly spread, irrespective of borders, countries, areas, communities, age, gender, etc. Speed and untowardness are the two strongest components of the crisis. ${ }^{1}$ The synergic effect of all of the listed aspects of the current Corona crisis causes the respect of all interested groups and also the need for professional crisis management at all levels, from the supra-national, through national, organizational to the individual level.

The crisis management theory is based on the basic model of crisis management, which consists of prevention, crisis planning, the start of a crisis phenomenon, subsequent reaction and recovery. ${ }^{2}$ In the case of the current crisis, given its specifics and mainly its unpredictable conditions, the tools of prevention and crisis planning did not work, or in many organizations existed only on a formal level and the crisis began with a fast and shocking onset of the acute stage of the crisis. In this environment, higher demands are placed on the competences of the management employees and on their responsibility for the consequences, which may arise due to unprofessional management and can paralyze an organization and its management employees. ${ }^{1}$ The sudden acute stage causes many negative emotions like fear, anxiety, anger and it also demands the need for security, trust and abilities to manage the crisis. ${ }^{3}$ The personality side of crisis managers and the ability to react adequately, fast and deliberately are very important aspects of crisis management at this stage. ${ }^{4}$

The aim of our research is to identify the impact of competent crisis management of healthcare facilities to manage a crisis in its acute stage. We have therefore examined the relation between the competences of crisis management, responsible for the decisions in a crisis situation in healthcare facilities and employee performance, whereby we assume that the competences of crisis management are positively related to employee performance through the sharing of information, teamwork and cognitive diversity of the work teams.

We have examined the relations between said variables at a time, when the pandemic happened and caused authentic, legitimate reactions of managers, who suddenly became crisis managers, forced to take on this role irrespective of their readiness. We consider the initial information to be very important because they have not been distorted by additional knowledge and they have truthfully uncovered the actual skills and abilities of crisis managers. As Bowers et $\mathrm{al}^{5}$ state, the dynamic of crisis compresses the time and space for taking actions and making decisions. A frequent issue in the development of crises is the fact that the organizations cannot identify the potentially conflicting issue at its early stage, which does not allow them to create an action plan to manage the issue before the issue starts controlling them. Even in the case of Slovakia, the first steps could have been implemented much sooner, because the epidemic was obvious at the beginning of 2020 in China, and it could have been assumed that it would continue to spread at a fast pace. The managers of hospitals could have invested in crisis management and proactively managed the anticipated crisis. Instead, they were waiting and reacted only after the discovery of the first person infected by the Coronavirus. The subsequent characteristic escalation process subsequently introduces a natural loss of control, panic, chaos and reckless decisions and negative consequences for the managed teams.

Based on the above, there is a research gap that creating a basis for the formation of the research model of this study. It is about defining the content and impact of a manager's competence in health facilities in times of crisis on the performance of health professionals. This is expressed in the acute phase of the crisis through their subjectively perceived satisfaction, evaluation of working conditions and safety. Many studies examine the content of leadership quality and show the importance of cognitive diversity in leadership, inclusion as the value of learning teams, ${ }^{6,7}$ and the importance of information sharing, ${ }^{8,9}$ and teamwork, which are necessary during the providing of health services. Information sharing is a tool for involving healthcare teams in the delivery of quality healthcare 
based on their effective teamwork. ${ }^{10,11}$ In general, the impact of cognitive diversity on performance is considered positive, especially when the creative potential is important. In the acute phase of the crisis, the ability to think about alternatives for the next direction and eliminate uncertainty is important. According to these studies, organizations can by using appropriate competencies of crisis management influence the performance of employees.

Many studies indicate that management of effective communication (especially internal), use of suitable management style, adequate decision-making ability, establishment of an effective crisis team and the sharing of information among them are important factors in the context of effective crisis management especially, during the acute stage of the crisis. ${ }^{9,12-15}$ These aspects affect the work performance of employees and teams, which at a time of acute healthcare crisis can be evaluated by their feeling of satisfaction, safety, and creation of conditions for work. ${ }^{16}$

According to the Vanni ${ }^{17}$ study, the exposure of healthcare professionals to the COVID-19 infection negatively affects their psychosocial well-being, regardless of gender, age and job classification, as well as the direct intensity of the threat, which is subsequently reflected in their performance.

Only the combined effect of said factors is the prerequisite of successful management of difficult conditions and preparations for new, often changed post-crisis operation. The reaction to the crisis defines the trajectory of recovery and the future for the organizational performance. $^{5}$ During healthcare crises, extremely high demands are placed on healthcare managers in the form of managing professional and management crisis competences at the same time. Together with this, the constant discussion on the insufficient management expertise of these managers comes into focus, ${ }^{18}$ because they are key medical specialists and were appointed for the management position due to these professional skills. They are missing basic management skills, they have a problem implementing innovative management tools, which introduce major effects in the business world and therefore we must not be surprised if they lack the necessary skills to be a current crisis manager to deal effectively with the new conditions, in which the organizations now have to operate. It is the technological development, e-environment, use of social media, demographic structure of the employees linked to their different views of the world of work and attitude towards it, their way of life and the effort to achieve a good work-life balance, and many others.

In the context of healthcare crises caused by various viruses, such as Zika, SARS, H1N1, and MERS, likewise in the case of the current COVID-19 pandemic, crisis communication is considered one of the most important areas of crisis management. It is expected that effective communication during the crisis reduces uncertainty, which can cause an emotional reaction of the public or the employees; therefore, stringency is one of its important elements. ${ }^{19,20}$

The results of a study by the Bai et $\mathrm{al}^{21}$ emphasize the value of unambiguous, exact information in reducing uncertainty for healthcare professionals at the time of the SARS epidemic. According to the authors of this study, in order to reduce uncertainty and minimize their stigmatization, it is necessary to provide healthcare professionals with accurate and updated information.

By analyzing the content of the communication messages of the leaders during the MERS healthcare crisis, You and $\mathrm{Ju}^{22}$ have discovered the tendency to communicate more their control over the crisis situation than their providing of clear information about what is happening together with a display of empathy.

Johansson and Ottestig ${ }^{23}$ found that managers overrate the importance of external compared to internal factors and this is manifested in insufficient communication skills in relation to the employees.

Boin et $\mathrm{al}^{19}$ state as the main parameters of communication of leaders in crisis, the ability to offer a reliable explanation of what has happened, provide directions to manage the spread of the virus, instill hope by emphasizing positive aspects and positively present the likelihood of successful solution of problems, express empathy towards their patients and families, healthcare workers and others affected by the healthcare crisis and constantly suggest that the management is in control of the situation, emphasize their own responsibility and take the appropriate steps to overcome the crisis situation. Reynold and Seeger ${ }^{24}$ see in internal communication the importance of encouraging individuals, which leads to an adequate and desired reaction. The research also found that regular communication on the effects of measures adopted in relation to preventing the virus from spreading leads to their higher observation. ${ }^{11}$ Coombs $^{25}$ states that communication on the part of the management should be perceived by the employees as honest, sincere, trustworthy and it should be transparent and open. 
Despite the existence of various opinions on leadership at a time of crisis in the scientific literature, we start with the context of the healthcare crisis and its specifics and the forming aspects of the leadership style of the crisis managers. James et $\mathrm{al}^{26}$ point out the forming of effective styles of management under the influence of expectations, which the employees have for their managers. In times of crisis, it is especially important because the employees are the key stakeholders in crisis management. During a crisis, the employees expect their leader to successfully master the crisis and easily overcome difficult obstacles. They want to trust in him, they need his support, they want to feel his interest and empathy and consequently, they want to be helpful through cooperation and shared leadership. ${ }^{13}$

During the acute stage of a crisis, in addition to communication and leadership, the ability to decide quickly and purposely is one of the most important skills of a crisis manager. Decision making during a crisis is linked to a high level of insecurity, which in the case of the COVID19 pandemic increases the low level of control over this new type of virus. Hirsch et $\mathrm{al}^{27}$ state that the adoption of clear goals and structures helps introduce security where there is great insecurity, which is characteristic of the acute times of crisis. Important prerequisites for a correct decision are the ability to think critically, perceive information in context and be oriented in the problem. ${ }^{28}$ At a time of crisis, it is necessary for the leadership to be able to analyze different solution possibilities, learn on the go from situations that are actually happening and flexibly respond to them, which is related to the existence of an effective crisis management in the time before the crisis. ${ }^{29}$ Recently, the need for cognitive diversity of the crisis team has become an integral part of crisis decision-making, which introduces different views of the situation and possibilities for its solution. ${ }^{30,31}$
Given the internal focus of crisis management, during the acute stage of the crisis, the crisis managers should ensure the higher performance of their teams by sharing information across their entire organization the correct extent, quality and time. ${ }^{9}$ Important aspects of information sharing are also clarity, regularity, and timeliness of informing about the current problems and facts, which subsequently lead to team performance. $^{11}$

Based on this research of literature, we have extracted the most frequently appearing items within the communication skills, leadership, and decision-making, which we have used to create a starting variable called Competences of Crisis Management [CCM]. All items, which are part of the CCM are listed in Table 1.

The quality of crisis management relates to the performance of the managed organization at a time of crisis. ${ }^{9,32,33}$ We assume that the CCM will lead to a higher performance of the managed teams, defined in the conditions of the acute stage of the crisis ${ }^{16}$ by the sharing of information, use of teamwork and cognitive diversity of the crisis management of the organization. We have formulated the main research hypothesis as follows:

$\mathrm{H}$ : The dependencies between the CCM and Team Performance [TP] are facilitated by sharing of information, teamwork and cognitive diversity of crisis management.

In verifying the validity of the main hypothesis, we have started with seven partial hypotheses.

H1. Crisis management competences are positively associated with team performance.

$\mathrm{H} 2$. CCM are positively associated with the sharing of information during a crisis.

$\mathrm{H} 3$. The sharing of information during a crisis is positively associated with team performance.

Table I Correlation Matrix. Source: Own Research

\begin{tabular}{|l|l|l|l|l|l|l|l|l|l|l|l|}
\hline Variables & Mean & SD & CCM & TW & SI & CD & TP & Age & Gender & Position & Experience \\
\hline CCM & 3.53 & 1.13 & & & & & & & & \\
TW & 3.55 & 0.98 & $0.93^{* *}$ & & & & & & \\
SI & 3.58 & 1.11 & $0.91^{* *}$ & $0.84^{* *}$ & & & & & \\
CD & 3.73 & 0.97 & $0.36^{* *}$ & $0.36^{* *}$ & $0.29 * *$ & & & & & \\
TP & 3.62 & 1.03 & $0.90^{* *}$ & $0.87^{* *}$ & $0.86^{* *}$ & $0.51^{* *}$ & & & & \\
Age & 2.22 & 0.53 & $0.24^{* *}$ & $0.26^{* *}$ & $0.19^{* *}$ & 0.08 & $0.26^{* *}$ & & & \\
Gender & 1.58 & 0.49 & $0.34^{* *}$ & $0.28^{* *}$ & $0.38^{* *}$ & 0.01 & $0.31^{* *}$ & 0.04 & & \\
Position & 2.40 & 0.98 & $0.31^{* *}$ & $0.27^{* *}$ & $0.26^{* *}$ & -0.02 & $0.19^{* *}$ & $0.20^{* *}$ & -0.04 & & \\
Experience & 3.66 & 0.61 & $0.23^{* *}$ & $0.22^{* *}$ & $0.23^{* *}$ & $0.27^{* *}$ & $0.27^{* *}$ & $0.52^{* *}$ & 0.05 & $0.21^{* *}$ & \\
Size & 224 & 0.83 & -0.05 & 0.03 & -0.01 & -0.05 & 0.01 & -0.06 & $-0.16^{* *}$ & -0.04 & $0.16^{* *}$ \\
\hline
\end{tabular}

Notes: Source: Own processing; ${ }^{* *} p>0.05$.

Abbreviations: CCM, competences of crisis management; TW, team work; SI, sharing of information; CD, cognitive diversity; TP, team performance. 
H4. CCM are positively associated with the level of teamwork during a crisis.

H5. The level of teamwork during a crisis is positively associated with team performance.

H6. CCM are positively associated with the level of cognitive diversity of crisis management.

H7. The level of cognitive diversity of crisis management is positively associated with team performance.

Figure 1 depicts the formulated relations.

\section{Materials and Methods Design and Procedure}

The questionnaires were sent electronically to mid-level healthcare managers (chief physicians, head nurses) in healthcare facilities in Slovakia. They were deliberately not distributed to top managers due to the distortion of their answers by their subjective view of their work, often perceived differently from their direct subordinates. Likewise, for the objective evaluation of management skills of crisis managers during an acute crisis, the questionnaires were sent and collected during the first month after the outbreak of the crisis (during the months of March-April 2020), whereby the first COVID-19 case in Slovakia was confirmed on 6th March 2020. At this time, the crisis managers had to face many unexpected and unknown issues and they had to solve various questions of the health of the population, employees, crisis operation of healthcare facilities, securing personnel, its safety and quality work conditions in pandemic conditions. The research sample consisted of 216 managers of different types of healthcare facilities operating throughout Slovakia. Table 2 describes its detailed characteristics.

The SPSS 22 software package has been used for data analysis. The reliability of the defined sets of items for individual variables (CCM, TP, SI, TW, CD) was tested using Cronbach's Alpha Coefficient. The correlation analysis was used to test the relations between the sets of items compiled for the assessment of individual variables. Subsequently, Baron and Kenny's Mediator Model was used and Freedman-Schatzkin's test was used to test the mediator effect. In the end, regression analysis was used to verify the proposed hypotheses. The control variables were the size of the healthcare facility based on the number of employees, gender and age of the manager, their position in the management hierarchy and experience in a management position. The ANOVA variance analysis was used to analyze multiple dependency. We have worked with a $5 \%$ level of significance.

\section{Measurements}

A mediator model was used to test the relations between Competences of Crisis Management (CCM), Team Performance (TP) and the mediating variables of Sharing of Information (SI), Team Work (TW) and Cognitive Diversity (CD). We deal with mediation because thanks to it we can examine the causal relations between the variables and engage further variables into the basic

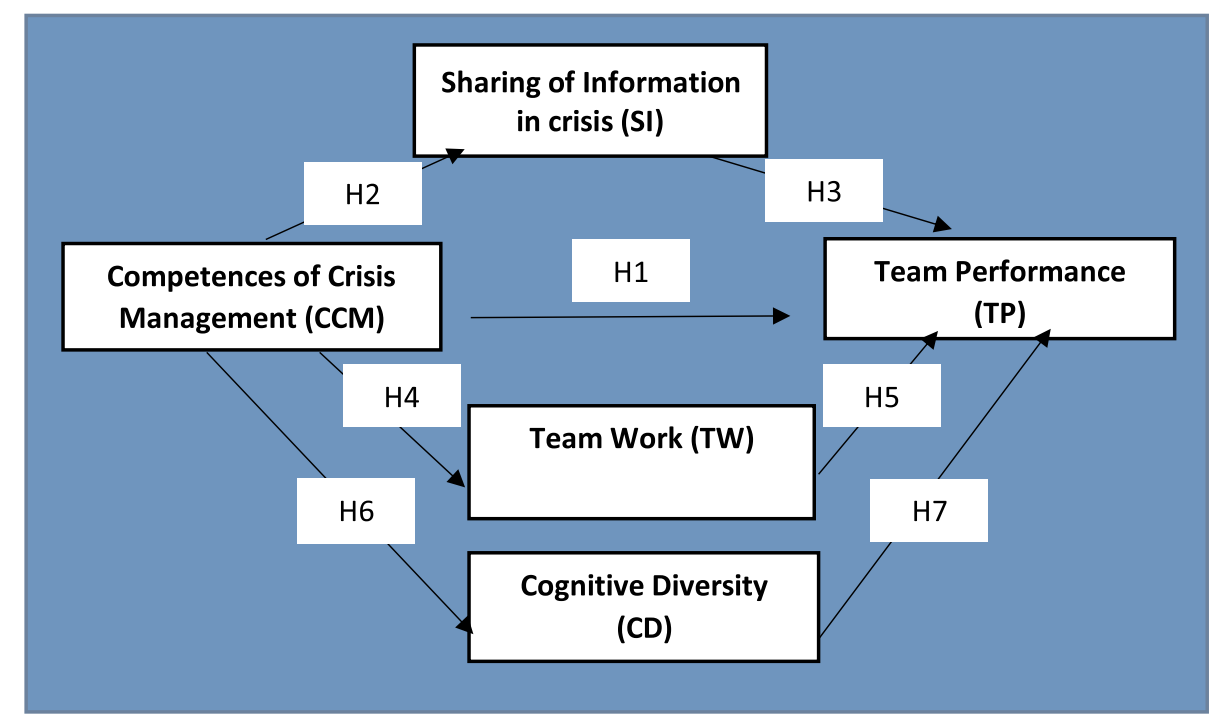

Figure I The mediation model and the seven tested hypothesis.

Notes: Source: Own processing; the individual variables are explained in the "measurements" section.

Abbreviations: CCM, competences of crisis management; CD, cognitive diversity; SI, sharing of information in crisis; TP, team performance; TW, team work. 
Table 2 Sample Characteristics

\begin{tabular}{|c|c|c|c|c|c|c|c|}
\hline Variables & Category & Frequency & Percent & Variables & Category & Frequency & Percent \\
\hline Number of employees & $\begin{array}{l}\text { Less than } 10 \\
1 \mathrm{I}-50 \\
5 \mathrm{I}-250 \\
\text { Over } 250 \\
\text { Total }\end{array}$ & $\begin{array}{l}10 \\
24 \\
86 \\
69 \\
216\end{array}$ & $\begin{array}{l}4.6 \\
11.1 \\
39.8 \\
44.4 \\
100.0\end{array}$ & Ownership & $\begin{array}{l}\text { Private } \\
\text { State } \\
\text { Total }\end{array}$ & $\begin{array}{l}92 \\
124 \\
216\end{array}$ & $\begin{array}{l}42.6 \\
57.4 \\
100.0\end{array}$ \\
\hline Position & $\begin{array}{l}\text { Informed Employee } \\
\text { Low man. } \\
\text { Middle man. } \\
\text { Higher man. } \\
\text { Total }\end{array}$ & $\begin{array}{l}54 \\
46 \\
92 \\
24 \\
216\end{array}$ & $\begin{array}{l}25.0 \\
21.3 \\
42.6 \\
11.1 \\
100.0\end{array}$ & Years of experience as manager & $\begin{array}{l}\text { Less Than I Year } \\
\text { Less than } 5 \\
6 \text { to } 10 \text { Years } \\
\text { Over } 10 \text { Years } \\
\text { Total }\end{array}$ & $\begin{array}{l}2 \\
10 \\
48 \\
156 \\
216\end{array}$ & $\begin{array}{l}0.9 \\
4.6 \\
22.2 \\
72.2 \\
100.0\end{array}$ \\
\hline Gender & $\begin{array}{l}\text { Male } \\
\text { Female } \\
\text { Total }\end{array}$ & $\begin{array}{l}90 \\
126 \\
216\end{array}$ & $\begin{array}{l}41.7 \\
58.3 \\
100.0\end{array}$ & Age of manager & $\begin{array}{l}\text { Under } 30 \\
30 \text { to } 50 \text { Years } \\
\text { Over } 50 \text { Years } \\
\text { Total }\end{array}$ & $\begin{array}{l}12 \\
144 \\
60 \\
216\end{array}$ & $\begin{array}{l}5.6 \\
66.7 \\
27.8 \\
100.0\end{array}$ \\
\hline Education & $\begin{array}{l}\text { Sec. school } \\
\text { Spec. management } \\
\text { Uni of I. Deg. } \\
\text { Uni of 2. Deg. } \\
\text { Uni of 3. Deg. } \\
\text { Total }\end{array}$ & $\begin{array}{l}10 \\
32 \\
6 \\
124 \\
44 \\
216\end{array}$ & $\begin{array}{l}4.6 \\
14.8 \\
2.8 \\
57.4 \\
20.4 \\
100.0\end{array}$ & & & & \\
\hline
\end{tabular}

Note: Source: Own processing.

relation to better and more deeply examine the relations and processes occurring between the identified variables.

The CCM represent an independent explanatory variable. This variable is operationalized as a score, which the crisis management of the healthcare facility received based on the evaluation of three items - crisis communication, management styles in a crisis and decision-making in a crisis. Every evaluated item consists of partial items. Overall, the CCM independent variable contains 26 items, which are scaled using 5-point Likert-type scales ( $1=$ "strongly disagree" and 5= "strongly agree"). After reliability analysis, the Cronbach's Alpha of the CCM was 0.958 (26 items).

To measure the variable, we used items divided into three areas:

Crisis communication - to measure this area, eight statements were used (for example: During a crisis, the leadership supports two-way communication). I view communication on part of the leadership during a crisis as honest, sincere and I trust it. I view communication on part of the leadership during a crisis as transparent.

Leadership style - to measure this area, 10 statements were used (for example: During a crisis, the leadership shows confidence in its employees also in cases when they encounter failure). During a crisis, the leadership provides the necessary support to the employees. During a crisis, the leadership empowers employees, provides the space for decision-making and acting, if they have the necessary skills).

Decision-making during crisis - to measure this area, these eight statements were used (for example: During a crisis, the leadership is able to critically evaluate information. During a crisis, the leadership is able to perceive information in context. During a crisis, the leadership is able to analyze different solution possibilities).

The second variable, seen as a consequence, is the Team Performance (TP) dependent variable. We follow the study of Kasha et $\mathrm{al}^{16}$, according to which items identifying the performance/effectiveness of the team depend on the environment and situation, in which the performance is measured. The creation of right and suitable conditions leads to improving the quality of teamwork and thus the achievement of the desired goals. In this stage of severe crisis, it is not possible to measure team performance using quantitative indicators, since they are not available yet. The assumption of effective operation and performance of a team during crisis conditions is the creation of such conditions for its operation, which in the subsequent crisis stage of assessing processes and creation of recommendations for the future would allow for measurable results to be excellent. The team performance 
variable is operationalized as the health care organization score assigned by heads of the departments to items representing satisfaction at work, feeling of safety and quality and secure work conditions. We have used the Safety Attitudes Questionnaire (SAQ), which has been validated by many studies, to compare the provisioning of health care, and which was designed specifically for the purpose of determining management attitudes towards questions of team work, from the perspective of teamwork environment, job satisfaction, perceptions of management, safety environment, working conditions, stress recognition also in extraordinary situations, which the current pandemic definitely is. ${ }^{34}$ After the reliability analysis, the Cronbach's Alpha of TP was 0.97 (17 items).

The level of sharing of information during crisis (SI), team nature of work (TW) and the level of cognitive diversity in work teams (CD) were identified as the mediator variables. These variables are a certain bridge between the dependent and the independent variable. They are directly inserted in their relation and affect the overall model. An independent variable is the cause of the mediator variable, which is then the cause of the dependent variable. ${ }^{35}$ Individual mediator variables are operationalized as the health care organization score given by heads of the departments to the selected items, which we have extracted from the above-listed literature research (Table 1). After the reliability analysis, the Cronbach's Alpha of the SI was 0.96 (10 items), TW 0.93 (9 items) and CD 0.89 (4 items).

The relation between the CCM, TP, SI, TW and CD variables may be affected by the so-called control variables. We have subsequently verified the effect of the control variables on the operation of the basic examined/ modeled relation.

\section{Results}

We determine the relations between the individual variables using a correlation matrix. For its construction, we have created summary variables - CCM, TP, SI, TW and $\mathrm{CD}$ as the overall average score of the corresponding items. The matrix also contains control variables. Descriptive statistics and the correlation matrix itself are presented in Table 1.

It is clear from the correlation matrix that there are significantly positive correlations between all five examined variables, which indicates the use of a mediator model. In mediation, we have started with the main set hypothesis.
$\mathrm{H}$ : The dependency between the competences of crisis management and team performance is mediated by sharing information, teamwork and cognitive diversity of crisis management.

We have proceeded in three steps (A, B, C), in which we will verify partial hypotheses by calculating three regressions.

C) There is a relation between team performance $(\mathrm{Y})$ and competences of crisis management (X).

A) There is a relation between the mediator variable (M) and competences of crisis management (X).

B) There is a relation between team performance $(\mathrm{Y})$ and mediator variable $(\mathrm{M})$, on which $\mathrm{X}$ does not participate.

where $\mathrm{C}$ represents the overall effect. The multiplication of $\mathrm{A} * \mathrm{~B}$ is the mediated (indirect) effect of $\mathrm{X}$ on $\mathrm{Y}$ via $\mathrm{M}$. The difference of $\mathrm{C}^{\prime}=\mathrm{C}-\mathrm{A} * \mathrm{~B}$ is the new (direct) effect of $\mathrm{X}$ on $\mathrm{Y}$ without $\mathrm{M}$.

The hypothesis is valid if the indirect effect is significant, so if $A^{*} \mathrm{~B}=\mathrm{C}-\mathrm{C}^{\prime}$ is significant (using Sobel's test). We have added control variables of age, gender, experience and position of a manager, size of the healthcare facility and its focus in the modeling of the overall effect. The ANOVA analysis of variance was used to analyze multiple dependencies. We have worked with the significance level of $5 \%$ and the obtained results are presented in Table 3. Since we work with three mediator variables, we will divide the structure of the model into three sections - three ways, in which the indirect, mediated relation will pass through each mediator. A path for a direct relation is also part of the model.

The analysis of variance for the overall dependency in the starting model indicated that education of the manager, type of healthcare facility and sphere (private or public), in which the facility operates (p-value < $0.05)$ are significant control variables. The mediator effect will be treated with these, since they have an effect on the course of the tested relations. The relation between the competences of crisis management and the gender of the manager $(p=0.48)$, his age $(p=0.71)$, amount of experience $(p=0.87)$, or the size of the healthcare facility $(\mathrm{p}=0.60)$ has not been proven.

The results in Table 3 clearly indicate that the overall indirect effect is significant in a positive direction just like all items of the indirect effect, mediated through individual mediators, are significant in the positive direction. Since the direct effect $\mathrm{C}$ is also significant, multilateral incomplete mediation has been 
Table 3 Parameter Estimates

\begin{tabular}{|c|c|c|c|c|c|c|c|}
\hline \multicolumn{8}{|c|}{ Step C: (Dependent Variable: TP) } \\
\hline Parameter & B & Std. Error & $\mathbf{t}$ & Sig. & \multicolumn{2}{|c|}{ Lower Limit } & Upper Limit \\
\hline Intercept & 1.15 & \multirow{2}{*}{$\begin{array}{l}0.31 \\
0.03\end{array}$} & 3.74 & 0.000 & \multicolumn{2}{|l|}{0.54} & 1.75 \\
\hline CCM & 0.83 & & 29.73 & 0.000 & \multicolumn{2}{|l|}{0.78} & 0.89 \\
\hline \multicolumn{8}{|c|}{ Steps AI, A2, A3: (Dependent Variable: SI) } \\
\hline Parameter & B & \multicolumn{2}{|l|}{ Std. Error } & Sig. & \multicolumn{2}{|c|}{ Lower Limit } & Upper Limit \\
\hline Intercept & 1.20 & \multirow{2}{*}{$\begin{array}{l}0.34 \\
0.03\end{array}$} & 3.50 & \multirow{2}{*}{$\begin{array}{l}0.001 \\
0.000\end{array}$} & \multicolumn{2}{|l|}{0.52} & 1.88 \\
\hline CCM & 0.91 & & 29.08 & & 0.85 & & 0.97 \\
\hline \multicolumn{8}{|c|}{ (Dependent Variable: TW) } \\
\hline Parameter & B & \multirow{3}{*}{$\begin{array}{l}\text { Std. Error } \\
0.29 \\
0.03\end{array}$} & $\mathbf{t}$ & \multirow{3}{*}{$\begin{array}{l}\text { Sig. } \\
0.001 \\
0.000\end{array}$} & \multirow{3}{*}{\multicolumn{2}{|c|}{$\begin{array}{l}\text { Lower Limit } \\
0.40 \\
0.71\end{array}$}} & Upper Limit \\
\hline Intercept & 0.98 & & 3.35 & & & & 1.56 \\
\hline CCM & 0.76 & & 28.36 & & & & 0.81 \\
\hline \multicolumn{8}{|c|}{ (Dependent Variable: CD) } \\
\hline Parameter & B & Std. Error & $\mathbf{t}$ & Sig. & \multicolumn{2}{|c|}{ Lower Limit } & Upper Limit \\
\hline Intercept & 4.12 & \multirow{2}{*}{$\begin{array}{l}0.65 \\
0.06\end{array}$} & 6.30 & \multirow{2}{*}{$\begin{array}{l}0.000 \\
0.000\end{array}$} & \multicolumn{2}{|l|}{2.83} & 5.41 \\
\hline CCM & 0.37 & & 6.10 & & 0.25 & & 0.48 \\
\hline Steps BI, B & t Varia & & & & & & \\
\hline Parameter & B & Std. Error & $\mathbf{t}$ & Sig. & $95 \%$ & onfiden & e Interval \\
\hline & & & & & Lowe & Limit & Upper Limit \\
\hline Intercept & -0.21 & 0.31 & -0.66 & 0.51 & -0.81 & & 0.40 \\
\hline CCM & 0.33 & 0.08 & 4.01 & 0.000 & 0.17 & & 0.49 \\
\hline SI & 0.32 & 0.06 & 5.55 & 0.000 & 0.21 & & 0.43 \\
\hline TW & 0.19 & 0.07 & 2.89 & 0.004 & 0.06 & & 0.32 \\
\hline$C D$ & 0.19 & 0.03 & 6.32 & 0.000 & 0.13 & & 0.25 \\
\hline Overall Indi & & & Indirect Effe & hrough & ediato & & \\
\hline & & & MI (SI) & & TW) & $\mathrm{M} 3(\mathrm{CL}$ & \\
\hline$A * B$ & 0.51 & $\mathrm{Ai} * \mathrm{Bi}$ & 0.29 & 0.1 & & 0.07 & \\
\hline z & 3.79 & zi & 5.46 & 2.8 & & 2.48 & \\
\hline Sig. & 0.000 & Sig. & 0.000 & 0.0 & & 0.013 & \\
\hline Effect Size & of the & & & & & & \\
\hline Effect & & & Coefficient & & $\%$ & & \\
\hline Overall & & & 0.84 & & 100 & & \\
\hline Direct & & & 0.33 & & 39 & & \\
\hline Indirect & & & 0.51 & & 61 & & \\
\hline Indirect & & & 0.29 & & 35 & & \\
\hline Indirect & & & 0.15 & & 18 & & \\
\hline Indirect & & & 0.07 & & 8 & & \\
\hline
\end{tabular}

Notes: Source: Own processing; $p>0.05$. Lower limit and upper limit are within the $95 \%$ confidence interval.

Abbreviations: CCM, competences of crisis management; TW, team work; SI, sharing of information; CD, cognitive diversity; TP, team performance.

verified. The size of the effect of individual components of the used model is shown in Table 3. Almost two thirds of the overall effect of crisis management competences on team performance are mediated by individual mediators, of which the sharing of information (35\%) has the greatest effect, $18 \%$ of the effect is mediated by team work and $8 \%$ by cognitive diversity of crisis management. 


\section{Discussion}

We proceed in the following steps $(\mathrm{A}, \mathrm{B}, \mathrm{C})$ in the interpretation of all acquired results:

- We have found that relations expressed in steps $\mathrm{A}$ and $\mathrm{B}$ are significant for all mediator variables; therefore, there are relations between the sharing of information (M1), team work (M2) and cognitive diversity (M3) and the competences of crisis management $(\mathrm{X})$ and that there are also relations between team performance $(\mathrm{Y})$ and all three mediator variables (M1, M2, M3), on which X does not participate. Due to the significance of these relations, the assumption for the existence of mediation arises.

- The multiplication of the $A * B$ parameters is significant, so the indirect effect of the competences of crisis management $(\mathrm{X})$ on team performance $(\mathrm{Y})$ through the measured sharing of information, teamwork and cognitive diversity was confirmed. The formulated hypothesis is therefore supported.

- The indirect and the direct effect are significant. Expressed in percent, we can see that about 39\% of the overall effect falls onto the direct effect and about $61 \%$ on the indirect effect. Since the indirect effect does not reach more than $80 \%$ of the overall effect, it is a partial mediation.

The hypothesis on the dependency between the competences of crisis management and team performance, which is mediated by sharing of information, teamwork and cognitive diversity was confirmed. Partial mediation has been identified when the mediator variables mediate only part of the effect. The remaining part, however smaller, is transferred directly. In each case it is a significant finding, which is that team performance in the stage of acute crisis may be affected by competent crisis management and amplify its effect, mostly by the sharing of information, supporting team work and also cognitive diversity of crisis management. Our findings are in line with many studies and findings, presented in scientific literature, where the important factors for crisis management, especially in its acute stage, are effective communication [especially internal], selection of suitable management style, flexibility of decision-making, creation of an effective crisis team and sharing of information within it. ${ }^{5,9,10,12-15}$

Crisis communication is one of the key elements of successful crisis management. Its importance is pointed out by several studies, ${ }^{12,36}$ which is also confirmed by the results of our research. According to Putnam and Nicotera, ${ }^{37}$ coworkers act based on how they understand the situation and they also discuss the crisis with all stakeholders, especially the patients. Reynolds and Seeger ${ }^{24}$ emphasize in internal crisis communication the importance of encouraging individuals, which subsequently leads to an adequate and desired behavior. Our findings similarly confirm the greatest effect of information background and sharing of the necessary information during the acute stage of the crisis on the teams' work results. This provides the employees with a feeling of safety and ensures the supply of information necessary for the quality performance of their work. The acquired results point out that the employees perceived communication of leadership in the examined healthcare facilities during the initial stages of the crisis as trustworthy; they had enough directions and information, which they have evaluated as useful. At the same time, it was difficult for them to express their critical opinions in case they saw issues. The statements of the respondents also indicate that the support, they needed for their work during this stage, they gave to each other; support on the part of the leadership was weaker. However, the respondents rated positively the speed and responsibility of the decision-making of the crisis management, its ability to learn on the go from situations, which is a prerequisite for the overall process of learning from the crisis in its subsequent stages. Based on research's results, clear, fast and reliable information sharing is a key attribute, competent of crisis management for healthcare teams and requires appropriate attention from managers.

Leadership is an important skill for health care managers, highly desirable in times of crisis because it helps build trust and develop support. Even in this case, the theory of social exchange applies, according to which such a leader obtains a much higher performance from his subordinates. Respondents added high values in their answers to the orientation of management in the problem, considering the moral and ethical consequences of their decisions and the fact that management was an example to employees during the acute phase of the crisis. The ability of management to show confidence in cases of failure is also important for the performance of employees at this stage, which is highly likely in uncertain and unfamiliar situations related to the coronavirus. Crisis leadership, amplified by teamwork in terms of our findings can be compared to the creating a new trend of lean leadership in healthcare, ${ }^{38}$ where lean leaders must constantly question 
current processes in order to improve them and involve all employees - not just managers - in identifying and solving problems. Transparency is mentioned as an important aspect of lean culture and it is considered essential to create an environment in which mistakes are seen as opportunities for learning, not to blame and discipline employees. Positive effects of lean management have been identified in relation to reduced error rates, reduced waiting times, reduced mortality, and higher patient safety. ${ }^{39}$ Our findings complement the positive effects of lean leadership in times of crisis, which are associated with job satisfaction, pride in work, enthusiasm to work in crisis conditions and the appropriate morale of teams and individual employees.

Intermediate variables have an important role in supporting management's crisis competencies in relation to team performance. Cooperation between team members is an unceasing topic in healthcare practice and the related scientific literature. ${ }^{40,41}$ Kunz et $\mathrm{al}^{42}$ also point out the importance of the existence of team standards, which determine the expectations for suitable behavior of individual team members. Middle management of healthcare facilities plays a key role in their forming, and the top management should recognize its importance in crisis management. According to Manser, ${ }^{40}$ middle management is also decisive for effective teamwork, especially in environments, which face a high level of clinical uncertainty and complexity. Research results have confirmed that teamwork in healthcare facilities was a supportive element of managing the initial stage of the crisis. The respondents rated autonomy, feeling of safety, ability to learn a lot and pride in their work very highly.

The exposure of healthcare professionals, alone to COVID-19 infection has a negative effect on their psychosocial well-being, they should be provided with psychological support in the workplace. According to Albott, direct contact with the COVID pandemic causes a high level of fear and anxiety among healthcare professionals, in the short term. Given the potentially widespread impact of COVID-19 on mental health, their protection against the adverse psychological effects of a pandemic is crucial. Suitable strategies may be, eg peer support, a model of mutual support, enabling the building of psychological resistance of healthcare professionals.

The effect of cognitive diversity of crisis management on the performance of the healthcare teams is the weakest among the examined mediator variables, but part of the effect is mediated also through it. This finding is in line with the research of Mitchell et $\mathrm{al}^{43}$, according to whom cognitive diversity affects the adoption of innovative solutions and process improvement based on the scope of professional knowledge, the inter-functional groups have. The involvement of diverse know-how and its use in crisis management may, to a lesser extent, increase the performance of teams in a crisis situation.

During a crisis of such enormous proportions, the current pandemic has placed great demands on healthcare managers, not only professional, medical but also in the field of crisis management. As the research results have confirmed, the education of the manager is directly related to its crisis competences, which creates a substantiated appeal on the expansion of management competences of healthcare leaders in many scientific studies. ${ }^{18,44-46}$ The reaction to the crisis determines the trajectory of recovery and the future of the organizational performance.

\section{Conclusion}

The study has several theoretical implications. It provides a comprehensive and timely review of the literature, determines what is already known about this topic, what are the current research gaps and tries to replenish them. It summarizes partial opinions on the crisis competencies of managers and brings a comprehensive view of the interrelationship of individual managerial competencies and their importance in influencing the performance of health care teams. Competence in management is a major factor for successfully managing pandemic in healthcare facilities.

Our findings offer valuable implications for the practice and the ability to draw conclusions from the leaderships of healthcare facilities during the initial stage of a crisis, when many negative emotions are present, such as fear, anxiety, anger, worry, and when this acute stage requires the need for certainty, trust and skills to manage the crisis.

The first important implication for the management of medical facilities is the cognition of the conditions, that are necessary for the effective employee performance. These include job satisfaction in difficult crisis conditions, the creation of a safe working environment and working conditions, support and reduction of stress. These are indicators through which management can detect and identify their wrong steps. Another practical implication is the finding, that in times of crisis, employees' performance is directly affected by competencies of management in the form of communications, leadership and decision-making. 
Employees demand honesty and sincerity, credible and transparent explanations, guidelines for managing the spread of the virus, but also empathy, encouragement and hope. An important aspect of leadership is creating a sense of control over the situation, trust and stability. For the performance of teams, it is necessary to make quick decisions based on the ability to perceive information in context and critically evaluate it. However, these competencies transfer their effect on team performance to a lesser extent than the transfer of their effect through information sharing and teamwork. Therefore, an important implication for the management of medical facilities is to strengthen the role of middle management in crisis management, which is involved in the gradual management of crisis, mainly through the transfer of information to employees and through the support of teamwork.

Based on our model of mediation, healthcare facilities, which strive to implement crisis management, should focus during the acute stage of a crisis especially on the information background and trustworthy, transparent and fast sharing of information, which supports the performance of the healthcare teams. The strategies for achieving these goals should include the education of the leadership team of the healthcare facility and its middle management, supporting management competences. Singer et $\mathrm{al}^{47}$ also highlight the need for leadership team training in a clinical environment, according to which, such education should suitably complement traditional educational approaches.

Each study has some important limitations that need to be stated and should be discussed. First, the research was conducted on a limited sample (216) of medical facilities in Slovakia. It is not possible to generalize local research on the territory of one country (Slovakia) in other countries, especially in case of corona crisis. From a regional point of view, the results are relevant.

\section{Abbreviations}

$\mathrm{CD}$, cognitive diversity; $\mathrm{CCM}$, competences of crisis management; SI, sharing of information in crisis; TP, team performance; TW, team work; WHO, World Health Organization.

\section{Data Sharing Statement}

The datasets used and analyzed during the current study are available from the corresponding author on reasonable request.

\section{Ethical Approval and Consent to Participate}

Ethical approval for the research was received from the Slovak Medical University, Faculty of Public Healthcare. All ethical aspects of the research were respected. The purpose of the research was explained to the respondents, they were motivated to provide data and the data were obtained with respect to the anonymity of the respondents.

By completing and submitting the questionnaire in writing, the participants agreed to participate in the study. Voluntary consent to participate in the study was fulfilled as a fundamental ethical principle, and at the same time as an essential part of the process of obtaining consent to participate in the study was to keep the participant fully informed about the objectives, proceedings, and risks of the study.

\section{Author's Contributions}

All authors made substantial contributions to conception and design, acquisition of data, analysis and interpretation of data; took part in drafting the article and revising it critically for important intellectual content; agreed to submit to the current journal; gave final approval of the version to be published; and agree to be accountable for all aspects of the work.

\section{Funding}

The research was supported by the Scientific Grant Agency of the Ministry of Education of the Slovak Republic and the Slovak Academy of Sciences VEGA (Project No. 1/0017/20: Changes in the implementation of management functions in the context of the fourth industrial revolution and adaptation processes in business in Slovakia). Research was also supported by the Scientific Grant Agency of the Ministry of Education of the Slovak Republic and the Slovak Academy of Sciences VEGA Project No. 1/0412/19: Systems of human resources management in the 4.0 Industry Era.

\section{Disclosure}

The authors declare that they have no conflicts of interest for this work.

\section{References}

1. Ali A. Complacency and crisis management in large organizations. Int J Commerce Manag. 2014;24:274-278. doi:10.1108/IJCoMA-072014-0085 
2. Bernstein J. The 10 steps of crisis communications; 2013. Available from: https://www.bernsteincrisismanagement.com/the-10-steps-ofcrisis-communications. Accessed June 26, 2020.

3. Liu X, Yang J. The research on influence of public security in significant emergency and management-QCA analysis based on Web crawler data of 32 events. J Risk Disaster Crisis Res. 2018;1:137-158.

4. Myer RA, Conte C, Peterson SE. Human impact issues for crisis management in organizations. Disaster Prev Manag. 2007;16:761-770. doi:10.1108/09653560710837055

5. Bowers MR, Hall JR, Srinivasan MM. Organizational culture and leadership style: the missing combination for selecting the right leader for effective crisis management. Bus Horiz. 2017;60:551-563. doi:10.1016/j.bushor.2017.04.001

6. Chow HIS. Cognitive diversity and creativity in teams: the mediating roles of team learning and inclusion. Chin Manag Stud. 2018;12:369-383. doi:10.1108/CMS-09-2017-0262

7. Jiang H, Zhang Q. Development and validation of team creativity measures: a complex systems perspective. Creativity Innov Manag. 2014;23:264-275. doi:10.1111/caim.12078

8. Srivastava A, Bartol KM, Locke EA. Empowering leadership in management teams: effects on knowledge sharing, efficacy, and performance. Acad Manag J. 2006;49:1239-1251. doi:10.5465/ amj.2006.23478718

9. Vainieri M, Ferrè F, Giacomelli G, Nuti S. Explaining performance in health care. Health Care Manage Rev. 2017. doi:10.1097/ hmr.0000000000000164

10. Lee TH, Cosgrove T. Engaging doctors in the health care revolution. Harv Bus Rev. 2014;6:104-111.

11. Vos SC, Buckner MM. Social media messages in an emerging health crisis: tweeting bird flu. J Health Commun. 2015;21:301-308. doi:10.1080/10810730.2015.1064495

12. Heide M, Simonsson C. Developing internal crisis communication. Corporate communications. Int J. 2014;2:128-146.

13. Pearce AP, Naumann DN, O'Reilly D. Mission command: applying principles of military leadership to the SARS-Cov-2 (covid-19) crisis. BMJ Military Health. 2020;bmjmilitary-2020-001485. doi:10.1136/ bmjmilitary-2020-001485

14. Shore DA. Today's leadership lesson: mind the wildlife and prepare for tomorrow's disruption. J Health Commun. 2020;25:301-302. doi:10.1080/10810730.2020.1749193

15. Bhaduri RM. Leveraging culture and leadership in crisis management. Eur J Train Dev. 2019;43:554-569. doi:10.1108/ejtd10-2018-0109

16. Kash BA, Cheon O, Halzack NM, Miller TR. Measuring team effectiveness in the health care setting: an inventory of survey tools. Health Services Insights. 2018;11:117863291879623. doi:10.1177/ 1178632918796230

17. Vanni G, Matterazzo M, Santori F, et al. The effect of Coronavirus (COVID-19) on breast cancer teamwork: a multicentric survey. In Vivo (Brooklyn). 2020;34(3 suppl):1685-1694. doi:10.21873/ invivo. 11962

18. Pihlainen V, Kivinen T, Lammintakanen J. Management and leadership competence in hospitals: a systematic literature review. Leadership Health Services. 2016;29:95-110. doi:10.1108/LHS-112014-0072

19. Boin A, Hart P, Stern E, Sundelius B. The Politics of Crisis Management: Public Leadership Under Pressure. Cambridge, UK: Cambridge University Press; 2016.

20. Helsloot I, Groenendaal J. It's meaning making, stupid! Success of public leadership during flash crises. J Contingencies Crisis Manag. 2017;25:350-353. doi:10.1111/1468-5973.12166

21. Bai Y, Lin -C-C, Lin C-Y, Chen J-Y, Chue C-M, Chou P. Survey of stress reactions among health care workers involved with the SARS outbreak. Psychiatr Services. 2004;55(9):1055-1057. doi:10.1176/ appi.ps.55.9.1055
22. You M, Ju Y. Salience of public leaders" "meaning making" in news coverage of a health crisis. Journal of Contingencies and Crisis Management. 2019;27:400-405. doi:10.1111/1468-5973.12259

23. Johansson C, Ottestig AT, L'Etang J. Communication executives in a changing world: legitimacy beyond organizational borders. J Commun Manag. 2011;15:144-164. doi:10.1108/ 13632541111126364

24. Reynolds B, Seeger MW. Crisis and emergency risk communication as an integrative model. $J$ Health Commun. 2005;10:43-57. doi:10.1080/10810730590904571

25. Coombs WT. Protecting organization reputations during a crisis: the development and application of situational crisis communication theory. Corp Reput Rev. 2007;10:163-176. doi:10.1057/palgrave. crr. 1550049

26. James EH, Wooten LP, Duskek K. Crisis management: informing a new leadership research agenda. Acad Manag Ann. 2011;5:455-493. doi:10.5465/19416520.2011.589594

27. Hirsh JB, Mar RA, Peterson JB. Psychological entropy: a framework for understanding uncertainty-related anxiety. Psychol Rev. 2012;119:304-320. doi:10.1037/a0026767

28. Higgins G, Freedman J. Improving decision making in crisis. J Bus Contin Emer Plan. 2013;1:65-76.

29. Reeves M, Lang N, Carlsson-Szlezak P. Lead your business through the Coronavirus; 2020. Available from: https://hbr.org/2020/02/leadyour-business-through-the-coronavirus-crisis. Accessed May 20, 2020.

30. Van der Vegt GS, Janssen O. Joint impact of interdependence and group diversity on innovation. J Manag. 2013;5:729-751.

31. Shin SJ, Kim TY, Lee JY, Bian L. Cognitive team diversity and individual team creativity: a crosslevel interaction. Acad Manag J. 2012;1:197-212.

32. MacLeod D, Clarke N. Engaging for Success: Enhancing Performance Through Employee Engagement, a Report to Government. Richmond Surrey: Office of Public Sector Information; 2011.

33. Spurgeon P, Mazelan PM, Barwell F. Medical engagement: a crucial underpinning to organizational performance. Health services management research. AUPHA. 2011;3:114-120.

34. McGuire MJ, Noronha G, Samal L, Yeh HC, Crocetti S, Kravet S. Patient safety perceptions of primary care providers after implementation of an electronic medical record system. J Gen Intern Med. 2013;2:184Y192.

35. MacKinnon DP. Multivariate Applications Series. Introduction to Statistical Mediation Analysis. Taylor \& Francis Group/Lawrence Erlbaum Associates; 2008.

36. Falkheimer J, Heide M. Crisis communicators in change: from plans to improvisations. In: Coombs WT, Holladay S, editors. Handbook of Crisis Communication. Malden, MA: Wiley-Blackwell; 2010:511-526.

37. Putnam LL, Nicotera AM. Communicative constitution of organization is a question: critical issues for addressing it. Manag Commun Quart. 2010;24:158-165. doi:10.1177/0893318909351581

38. Abuhejleh A, Dulaimi M, Ellahham S. Using lean management to leverage innovation in healthcare projects: case study of a public hospital in the UAE. BMJ Innov. 2016;2:22-32. doi:10.1136/bmjinnov-2015-000076

39. Aij KH, Rapsaniotis S. Leadership requirements for Lean versus servant leadership in health care: a systematic review of the literature. J Healthc Leadership. 2017;9:1-14. doi:10.2147/JHL. S120166

40. Manser T. Teamwork and patient safety in dynamic domains of healthcare: a review of the literature. Acta Anaesthesiol Scand. 2009;53:143-151. doi:10.1111/j.1399-6576.2008.01717.x

41. Weller J, Boyd M, Cumin D. Teams, tribes and patient safety: overcoming barriers to effective teamwork in healthcare. Postgrad Med J. 2014;90:149-154. doi:10.1136/postgradmedj-2012-131168 
42. Kuntz L, Scholten N, Wilhelm H, Wittland M, Hillen HA. The benefits of agreeing on what matters most. Health Care Manage Rev. 2018. doi:10.1097/hmr.0000000000000220

43. Mitchell RB, Boyle R, O’brien A, et al. Balancing cognitive diversity and mutual understanding in multidisciplinary teams. Health Care Manage Rev. 2017;42:42-52. doi:10.1097/HMR.0000000000000088

44. Ackerly DC, Sangvai DG, Udayakumar K, et al. Training the nex generation of physician-executives: an innovative residency pathway in management and leadership. Acad Med. 2011;86:575-579. doi:10.1097/ACM.0b013e318212e51b

45. Enterkin J, Robb E, McLaren S. Clinical leadership for high-quality care: developing future ward leaders. J Nurs Manag. 2013;21:206-216. doi:10.1111/j.1365-2834.2012.01408.x
46. Yoder-Wise PS. The future of leadership. $J$ Nurs Admin. 2014;44:318-320. doi:10.1097/NNA.0000000000000075

47. Singer S, Lin S, Falwell A, Gaba D, Baker L. Relationship of safety climate and safety performance in hospitals. Health Serv Res. 2009;44:399-421. doi:10.1111/j.1475-6773.2008.00918.x

\section{Publish your work in this journal}

Risk Management and Healthcare Policy is an international, peerreviewed, open access journal focusing on all aspects of public health, policy, and preventative measures to promote good health and improve morbidity and mortality in the population. The journa welcomes submitted papers covering original research, basic science, clinical \& epidemiological studies, reviews and evaluations, guidelines, expert opinion and commentary, case reports and extended reports. The manuscript management system is completely online and includes a very quick and fair peer-review system, which is all easy to use. Visit http://www.dovepress.com/testimonials.php to read real quotes from published authors.

Submit your manuscript here: https://www.dovepress.com/risk-management-and-healthcare-policy-journal 